\section{ECCOMAS}

Proceedia
COMPDYN 2021

$8^{\text {th }}$ ECCOMAS Thematic Conference on Computational Methods in Structural Dynamics and Earthquake Engineering M. Papadrakakis, M. Fragiadakis (eds.) Streamed from Athens, Greece, 28 - 30 June 2021

\title{
A SIMPLE METHODOLOGY FOR THE INFILL MASONRY WALL STIFFNESS ESTIMATION
}

\author{
Vanni Nicoletti $^{1}$, Davide Arezzo ${ }^{1}$, Sandro Carbonari ${ }^{1}$, and Fabrizio Gara ${ }^{1}$ \\ ${ }^{1}$ Dept. ICEA, Università Politecnica delle Marche \\ Via Brecce Bianche, 60131, Ancona, Italy \\ e-mail:v.nicoletti@pm.univpm.it, d.arezzo@pm.univpm.it, s.carbonari@univpm.it, f.gara@univpm.it
}

\begin{abstract}
The importance of assessing the overall dynamic behavior of buildings considering the contribution of infills is nowadays widely recognized considering that they play an important role in the verifications at damageability limit states and, at ultimate limit states, they can trigger fragile mechanisms of structural members preventing the evolution of dissipative ones. In addition, in case of strategic structures, for which often high performance levels are required such as the full operativity condition (i.e. absence of damage to both structural and non-structural components) after severe earthquake, the contribution of non-structural members should be necessarily included in the seismic assessment.

The paper proposes a simplified procedure for estimating the stiffness of masonry infill walls through expeditious dynamic impact tests. Stiffness can be adopted to model infills into conventional 3-D finite element models of buildings. The procedure is validated by means of an experimental campaign carried out on a laboratory real-scale mock-up and then applied to a real infilled reinforced concrete frame building. Experimental results are compared with those obtained from refined finite element models including infills, proving the methodology reliability.
\end{abstract}

Keywords: Infill masonry wall stiffness, impact load tests, experimental modal analysis, ambient vibration tests, building finite element modelling. 


\section{INTRODUCTION}

Infill masonry walls are very common components used worldwide in r.c. frame buildings and nowadays it is well known that the stiffness and strength, together with the mass, provided by these non-structural elements may significantly affect the global behavior of buildings, especially in earthquake prone regions [1-4]. The common practice of modelling infills within building f.e. models only in terms of masses is recognized to be not correct, particularly when the f.e. models must be representative of the real building behavior. As an example, the prediction of the real building behavior subjected to earthquake becomes crucial in case of strategic buildings (e.g. hospital, fire and police stations) that must remain in operational condition to guarantee the post-earthquake emergency management [5-6]. Moreover, reliable f.e. models of buildings, i.e. capable to represent the building operational conditions, could be very useful to develop Structural Health Monitoring (SHM) systems [7-9] and to interpret data collected during the monitoring period, in order to assess the building conditions and to detect possible damage to the structural and non-structural members.

From above considerations it is evident the importance of modelling these non-structural components in a reliable manner. Many works in the technical and scientific literature deals with infill modelling strategies, from the simple adoption of a single diagonal strut [10-11] to refined linear and non-linear models [12-13]. Anyway, modelling uncertainties always exist and could affect the modelling correctness. Many researchers investigated the infill behavior with the aim of reducing these uncertainties: most of them studied infills subjected to static lateral loads [14-15], other adopted out of plane loads, and very few used dynamic tests on infills, as, for instance, Ambient Vibration Tests (AVTs) [16-17]. It clearly emerges that a standardization of the infill properties is almost impossible to achieve, considering they are built with different construction materials and typologies all around the world.

This paper proposes a procedure to estimate the stiffness of infill masonry walls that can be used to model these non-structural components within f.e. models of buildings. The proposed approach is based on a combined experimental and numerical procedure: the former foresees the development of dynamic tests on infills through which the modal parameters of the nonstructural components are identified; the latter consists in the development of a f.e. model of the structures in which the infills are modelled and investigated with the aim of estimating their stiffness, expressed in terms of elastic modulus. The proposed procedure is preliminary well described, then it is validated through the support of a real-scale laboratory mock-up, used as a case study. Finally, the methodology is applied to a real building to verify its applicability to real structures.

\section{THE PROPOSED METHODOLOGY}

The proposed methodology is a combined experimental and numerical procedure that foresees dynamic tests on infills and their numerical investigation through the support of f.e. models. In the sequel a summary of the methodology, is reported; for further details the reader can refer to $[18]$.

The dynamic tests performed on infill masonry walls are Impact Load Tests (ILTs) that allow the determination of the Out Of Plane (OOP) dynamic behavior of the non-structural components. ILTs consist in exciting the wall with hammer blows and in recording input and output in the horizontal direction, orthogonal to the wall plane. The output are the time histories of the accelerations produced by the impacts. To perform tests, an instrumented hammer and one or more accelerometers can be used: the accelerometer is fixed on a specified position on the wall, while hammer blows are applied in several points, with the target to identify the panel vibration modes, possibly considering also superior modes. The use of more than one sensor (or moving 
the sensor in different positions) may be useful to identify modes that present null value of modal displacement in proximity of the sensor position. The wall can be suitably divided with a regular grid whose spatial resolution depends on the accuracy and on the number of modes that have to be identified. The accelerometer is fixed in one grid point, while hammer blows are provided in all points, applying more than one impact for each of them, allowing to obtain a reliable data set. The impulse-acceleration data recorded are adopted to identify the OOP modal parameter of the panel, performing Single-Input Single-Output modal analyses. In the sequel, the Line-Fit algorithm [19] (a simple degree of freedom identification methodology working in the frequency domain) is adopted to identify the infill modal parameters.

The numerical step of the methodology consists in performing an iterative procedure with the aim of estimating the infill stiffness and, particularly, its elastic modulus. Indeed, despite masonry infills are generally characterized by an orthotropic behavior, the adopted strategy is based on the idea that the dynamics of infills subjected to low input excitations (like hammer blows) can be well captured through homogenous isotropic elastic thin plate elements. So, the stiffness of these non-structural components is mainly governed by the elastic modulus, assuming a constant Poisson's coefficient (e.g. 0.25 as suggested in [20]). At first, the investigated infill is modelled as bidimensional shell elements into the f.e. model of the bare frame structure, adopting its real thickness and with mass estimated based on the adopted construction materials, which are known in most cases. The first tentative elastic modulus $E_{0}$ of the infill can be calculated based on closed-form expressions available in the literature for clamped rectangular plates. Considering the formulation proposed in [21], the tentative elastic modulus is calculated as follows:

$$
E_{0}=\frac{48 \rho\left(1-v^{2}\right)}{\pi^{2} t^{2}} f_{1, \exp }^{2}\left[\left(\frac{1+\Delta_{m}}{l}\right)^{2}+\left(\frac{1+\Delta_{n}}{h}\right)^{2}\right]^{-2}
$$

where $\rho$ is the mass per unit area, $t$ is the wall thickness, $v$ is the Poisson's coefficient, $l$ and $h$ are the length and height of the wall, $f_{1, \exp }$ is the first OOP vibration mode frequency experimentally identified and $\Delta_{m}$ and $\Delta_{n}$ are the edge effect factors, that can be calculated as:

$$
\begin{aligned}
& \Delta_{m}=\left[\left(\frac{l}{h}\right)^{2}+2\right]^{-1}+0.017 \\
& \Delta_{n}=\left[\left(\frac{h}{l}\right)^{2}+2\right]^{-1}+0.017
\end{aligned}
$$

Then, eigenvalue analyses are performed and the numerical modal parameters relevant to the infill OOP dynamic behavior are determined. This procedure is performed several times, varying at each step the infill elastic modulus, until the numerical modal parameters fit well the experimental ones. In order to quantify the goodness of the estimated moduli, two convergence criteria are introduced, based on the comparisons of the experimental and numerical natural frequencies and mode shapes, respectively. When criteria satisfy the conditions reported in Eq.s $3 \mathrm{a}$ and $\mathrm{b}$, the estimating procedure stops and the elastic modulus is considered as representative for the wall at hand.

$$
\frac{\sum_{i=1}^{N} \frac{1}{i}\left|\frac{f_{i, \exp }-f_{i, \text { num }}}{f_{i, \exp }}\right|}{\sum_{i=1}^{N} 1 / i} \leq \delta_{f}
$$




$$
1-\frac{\sum_{i=1}^{N} \frac{M A C_{i}}{i}}{\sum_{i=1}^{N} 1 / i} \leq \delta_{s}
$$

In Eq.s $3 \mathrm{a}$ and $\mathrm{b} f_{i, \exp }$ and $f_{i, \text { num }}$ represent the $i$-th experimental and numerical frequency value of the total $N$ identified OOP vibration modes, while $M A C_{i}$ is the $i$-th Modal Assurance Criterion index [22] used to compare two mode shapes. $\delta_{f}$ and $\delta_{s}$ represent the admissible errors in the comparison between frequencies and mode shapes, respectively; in this work, values of $\delta_{f}$ $=0.05$ and $\delta_{s}=0.25$ are proposed and considered in the successive case studies.

As common in practice, r.c. frame structures are usually modelled with frame elements, so the area of modelled infills is greater than the real one since physical dimensions of columns and beams are neglected. Thus, when infills are modelled with shell elements within frame structure f.e. models, their dimensions (length and height) are greater than the real ones; consequently, to consider this approximation, the mass and stiffness of the modelled panel must be suitably modified. In detail, the mass density $\left(\rho_{m}\right)$ and the elastic modulus $\left(E_{m}\right)$ of the modelled infill are reduced by a factor $\lambda$ that represents the mean percentage increment of the panel dimensions for both sides:

$$
\begin{aligned}
& \rho_{m}=\rho / \lambda^{2} \\
& E_{m}=E / \lambda^{2}
\end{aligned}
$$

The estimation of infill elastic modulus, assuming the geometry and mass to be known, permits the reduction of the uncertainties and the updating of parameters in sophisticated f.e. models of infilled frame structures. Obviously, the elastic modulus estimated with this procedure permits to predict the infill behavior under low level of excitation and, consequently, it is useful when building behavior under low level of excitation needs to be interpreted. Indeed, as shown in the sequel, refined f.e. models of structures, obtained modelling the infill with the proposed approach, reveal to be able to well predict the structural responses under ambient vibration excitations.

\section{METHODOLOGY VALIDATION THROUGH A LABORATORY CASE STUDY}

The proposed methodology is applied on a laboratory mock-up considered as case study, experimentally tested, and then numerically investigated. The aim is to validate the proposed approach through an application to a simple structure under controlled laboratory conditions with limited uncertainties. The mock-up is a steel-concrete composite structure consisting of a pair of one-story two-bay moment-resisting frames with height of $3.00 \mathrm{~m}$ and span length of around $4 \mathrm{~m}$ (Fig. 1). Columns and beams are realized with steel profiles and the composite slab is obtained with a $12 \mathrm{~cm}$ thick concrete layer casted on a collaborating steel sheet. Some concrete blocks are placed over the composite floor to simulate permanent and live loads on the structure. Two infill walls (W1 and W2) are built with hollow clay bricks (dimension of $25 \times 25 \times 6 \mathrm{~cm}$ ) and mortar joints, filling only one of the two longitudinal bays. Successively, both sides of both walls are covered with a thin gypsum plaster layer (less than $1 \mathrm{~cm}$ ). This infill typology can be considered representative for the light infills adopted very often to realize interior partitions in common buildings. 

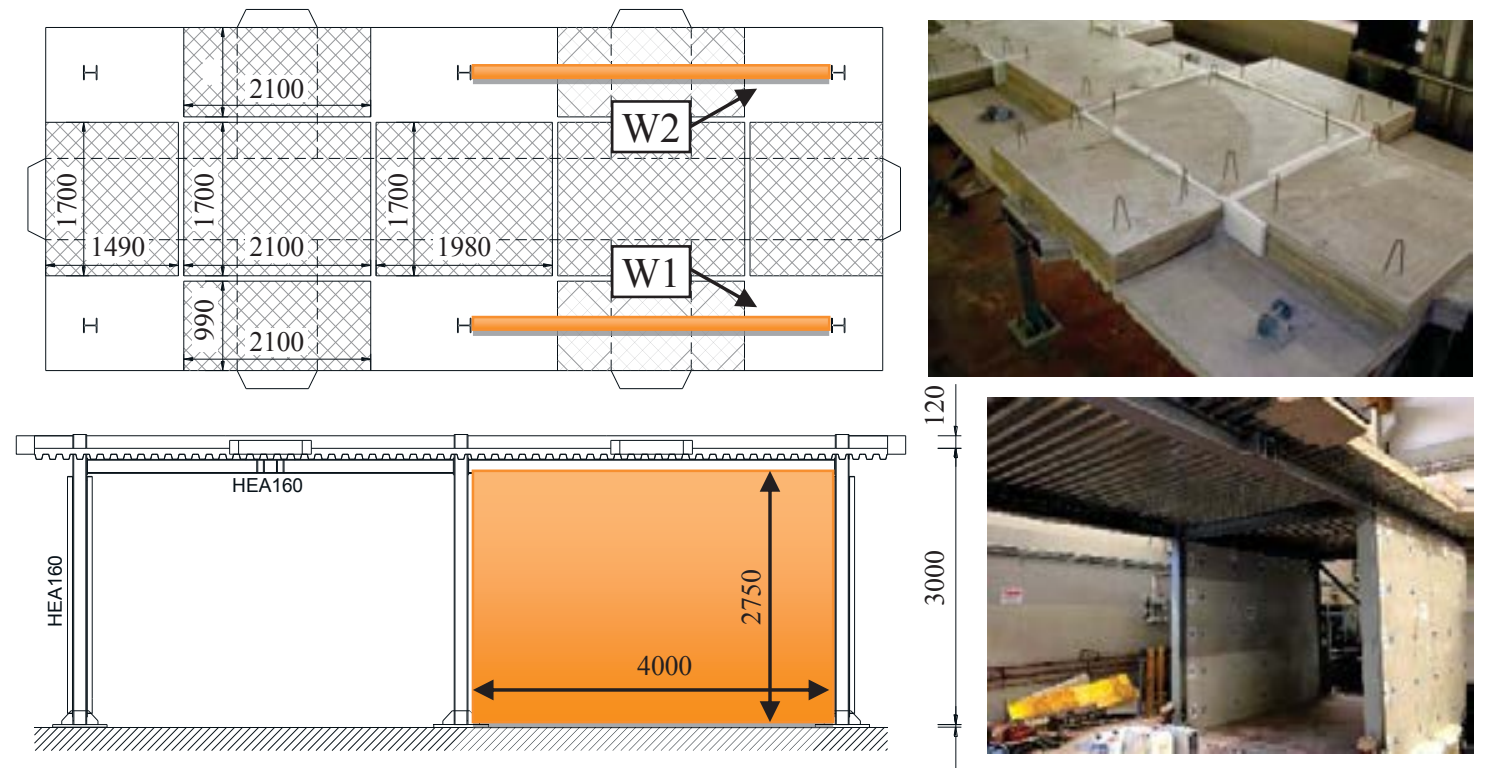

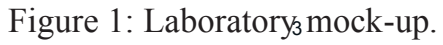

Both infills are dynamically tested through ILTs; for each of them, a regular grid of twentyfive points is drawn on a panel face and two accelerometers are fixed on the wall in two grid points with the target to identify as many vibration modes as possible. Then, hammer blows are provided at each grid point, recording both impulses and accelerations, for a time length of $10 \mathrm{~s}$ per impact, considered adequate to capture the entire oscillation. It is worth noting that both panels are tested twice, before and after the plastering. Based on acceleration and impact records, the OOP modal parameters of each infill are identified; in detail, many vibration modes are found, as can be observed from Tab. 1 and Fig. 2. Each mode is named with a couple of number that represent the number of semi waves present in the mode shape along the horizontal and vertical directions. Identified natural frequencies, listed in Tab. 1, show that both walls are characterized by almost the same frequency values, even if those relevant to W2 are slightly higher than those of W1. Moreover, after the plaster, all frequency values increase, as expected. Fig. 2 provides an example of the mode shapes of $\mathrm{W} 1$ with plaster. Those relevant to W2 are not reported, being very similar to $\mathrm{W} 1$.

To validate the proposed procedure, a 3-D full-shell element f.e. model of the bare mock-up is created (Fig. 3a). Moreover, this preliminary model is calibrated with the support of the global 3-D mock-up experimental modal parameters determined through AVTs performed on the bare structure. After that, the two infills are added in the calibrated f.e. model (Fig. 3b), both with shell elements having thickness equal to the real ones. Based on the experimental fundamental frequency of each wall, a first tentative elastic modulus $E_{0}$ is calculated. Values of 2445 and $2775 \mathrm{MPa}$ are calculated for $\mathrm{W} 1$, before and after plastering, respectively, while 2210 and $2420 \mathrm{MPa}$ are calculated for W2. At this point, iterative procedures are performed by varying the elastic modulus of each wall one by one, until the convergence criteria (calculated considering all the identified OOP modal parameters) are satisfied. The obtained elastic moduli at the end of the procedures are listed in Tab. 2; it is interesting to observe that the Young's moduli of the two walls are quite similar but not equal. After the plastering, the infill elastic moduli increase, mostly for W1. 
Table 1: Experimental natural frequencies for both infills without and with plaster.

\begin{tabular}{ccccc}
\hline \multirow{2}{*}{ Mode } & \multicolumn{3}{c}{ W1 } & \multicolumn{2}{c}{ W2 } \\
& No plaster & Yes plaster & No plaster & Yes plaster \\
\hline 1,1 & 16.80 & 17.30 & 17.90 & 18.10 \\
2,1 & 27.47 & 31.60 & 29.53 & 32.15 \\
1,2 & 40.10 & 49.00 & 48.00 & 49.97 \\
3,1 & 46.55 & 49.40 & 45.35 & 50.50 \\
2,2 & 57.54 & 63.88 & 59.20 & 64.50 \\
4,1 & 63.07 & 66.50 & 66.85 & 68.10 \\
5,1 & 76.85 & 120.71 & 78.93 & 119.90 \\
3,2 & 79.79 & 85.98 & 76.10 & 82.67 \\
2,3 & $/$ & 105.30 & $/$ & 107.13 \\
4,2 & 104.98 & 113.75 & 104.40 & 127.30 \\
3,3 & 117.77 & 131.19 & 119.40 & 133.20 \\
5,2 & 132.28 & 143.93 & 139.10 & 155.90 \\
5,3 & 177.60 & 198.85 & 175.24 & 212.50 \\
\hline
\end{tabular}
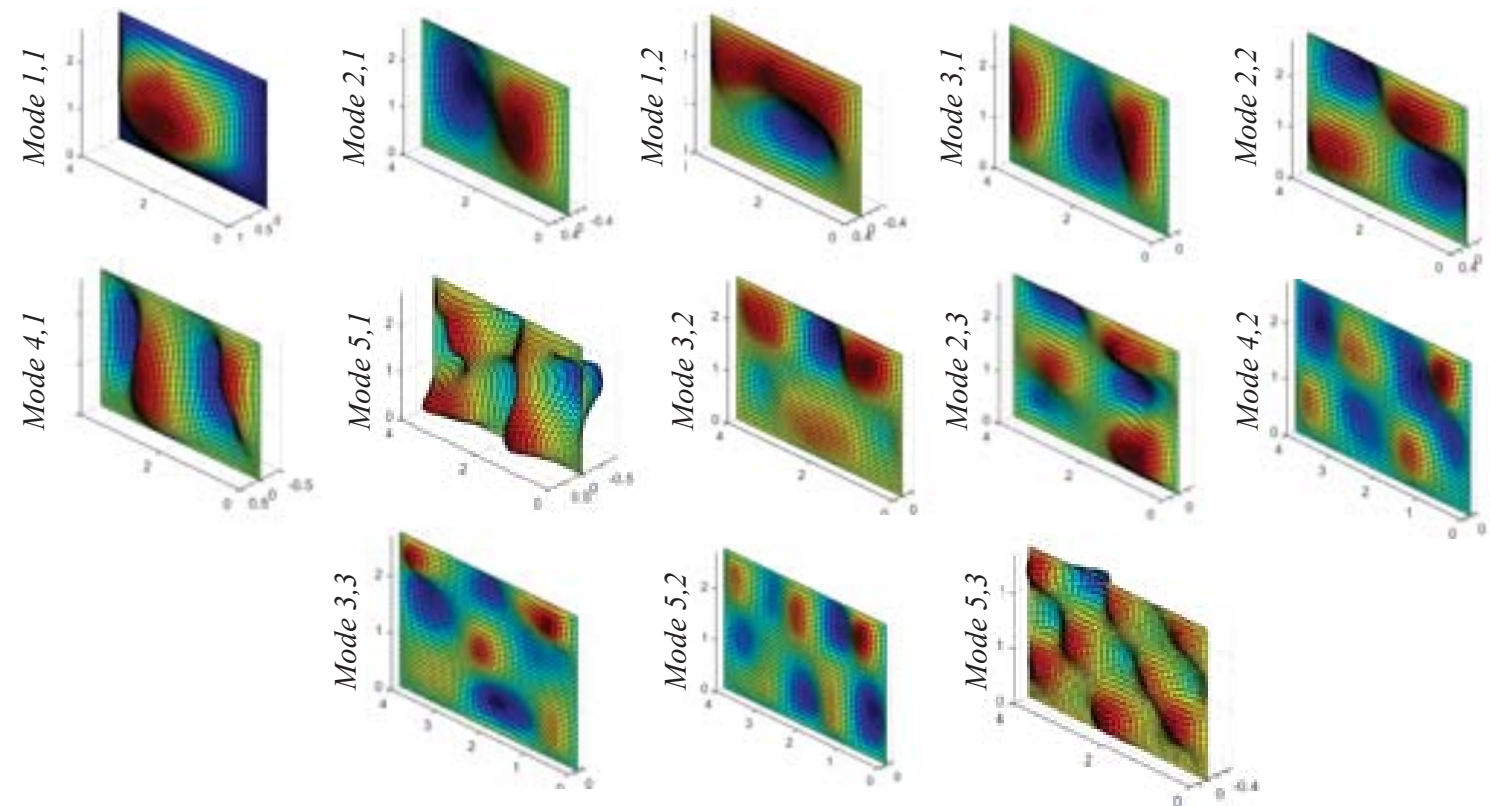

Figure 2: Experimental mode shapes for W1 with plaster.

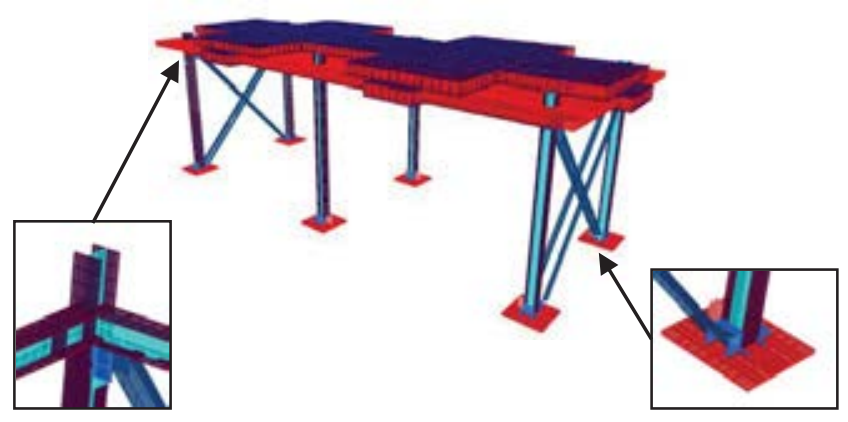

(a)

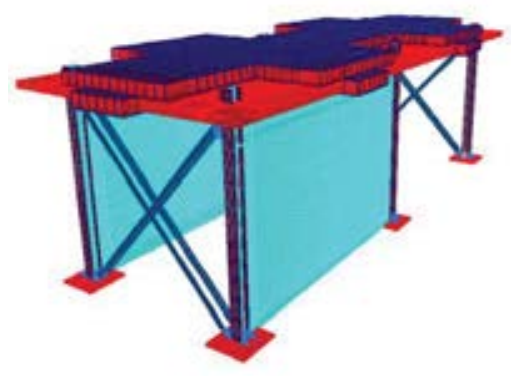

(b)

Figure 3: 3-D global f.e. model of the mock-up: a) bare structure, b) infilled structure. 
To assess the reliability of the estimated elastic moduli, the numerical modal parameters of the whole infilled mock-up (using the infill elastic moduli reported in Tab. 2) are compared with those obtained from AVTs performed on the whole infilled structure before and after the plastering. Comparisons, in terms of natural frequencies and mode shapes (the latter obtained through the MAC indexes), are reported in Tab. 3. As can be observed, the numerical modal parameters (NUM) are in very good agreement with the experimental ones (EXP), proving the reliability of the elastic moduli estimation. It is worth noting that, in this case, the mass densities and the elastic moduli used in the global f.e. model are not reduced since the modelled infill dimensions are the same of the real ones.

Table 2: Estimated elastic moduli $E$ for both infills without and with plaster.

\begin{tabular}{ccc}
\hline \multirow{2}{*}{ Wall } & \multicolumn{2}{c}{ Elastic modulus [MPa] } \\
& No plaster & Yes plaster \\
\hline W1 & 4700 & 4900 \\
W2 & 5340 & 5360 \\
\hline
\end{tabular}

Table 3: Comparison between experimental and numerical infilled mock-up modal parameters.

\begin{tabular}{cccccccc}
\hline \multirow{2}{*}{$\begin{array}{c}\text { Mock-up } \\
\text { mode }\end{array}$} & Mode typology & \multicolumn{3}{c}{ Before plaster } & \multicolumn{3}{c}{ After plaster } \\
& & Exequency [Hz] & MAC & \multicolumn{2}{c}{ Frequency [Hz] } & MAC \\
& & EXP & NUM & & EXP & NUM & \\
\hline $1^{\text {st }}$ & Transverse & 8.40 & 8.40 & 1.00 & 8.37 & 8.38 & 1.00 \\
$2^{\text {nd }}$ & Rotational & 12.72 & 12.94 & 0.93 & 13.39 & 13.08 & 0.97 \\
$3^{\text {rd }}$ & Longitudinal & 16.32 & 16.38 & 0.81 & 17.69 & 17.71 & 0.99 \\
\hline
\end{tabular}

\section{APPLICATION TO A REAL BUILDING CASE STUDY}

The proposed methodology is applied to a real building in order to prove its usefulness and applicability to real structures. The considered case study is a r.c. frame building (Fig. 4a) with plan dimensions of around $16.50 \times 11.70 \mathrm{~m}$ composed by two stories, for a total height of about $8.00 \mathrm{~m}$. The underground level is mainly realized by r.c. retaining walls, while the upper one is realized with spatial r.c. frames. The infill masonry walls are built both along the building perimeter and inside the building, and they can be divided into three main typologies, as reported in Fig. 4b: E1 is adopted for all external infills, I1 is adopted to separate the housing units within the building at the underground and ground levels, while I2 is adopted to realize all the interior partitions. The building was investigated and tested during its construction process; in detail, AVTs were performed on the bare and on the infilled structure, whereas ILTs on infills were performed only in the phase without plaster.

As for tests on infills, three infills representative for all the infills typologies are tested (WE1, W-I1 and W-I2). All walls are located at the ground floor and have no openings. The geometry of the tested infills is illustrated in Fig. 5. ILTs on the three infills are performed with the same instrumentation and test protocols adopted for tests on laboratory mock-up infills, and the infill OOP modal parameters are identified again using the Line-Fit algorithm. The experimental OOP modal parameters of the walls are reported in Fig. 6, both in terms of frequencies and mode shapes. As can be observed, four vibration modes are identified for each infill. 

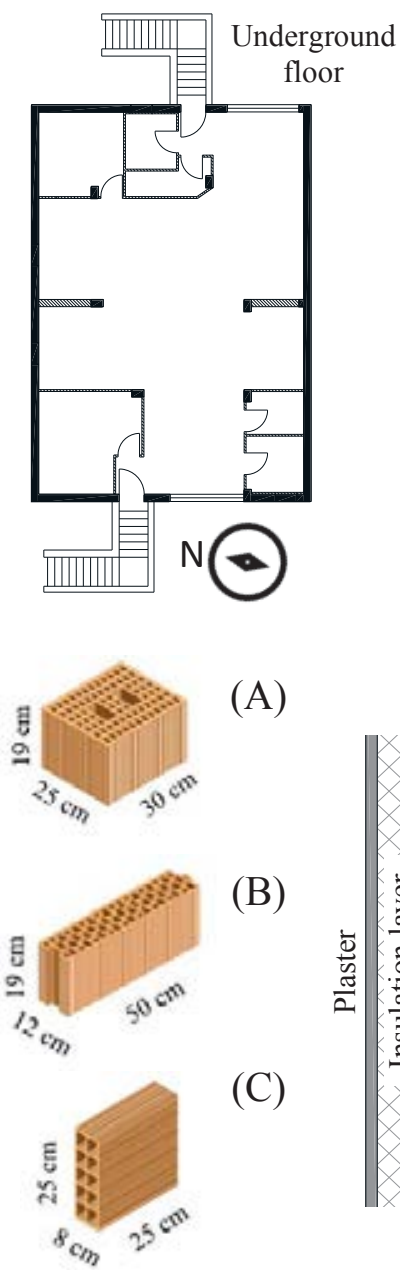

(A)

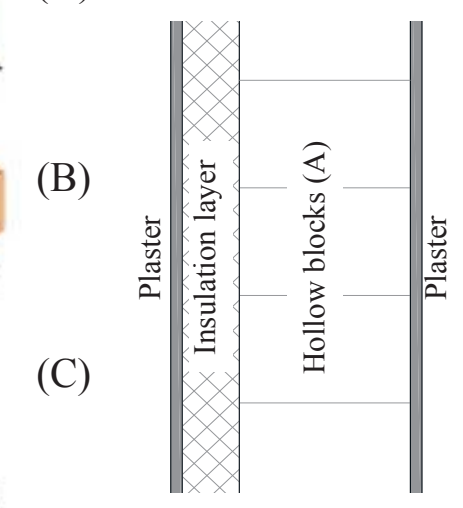

(a)

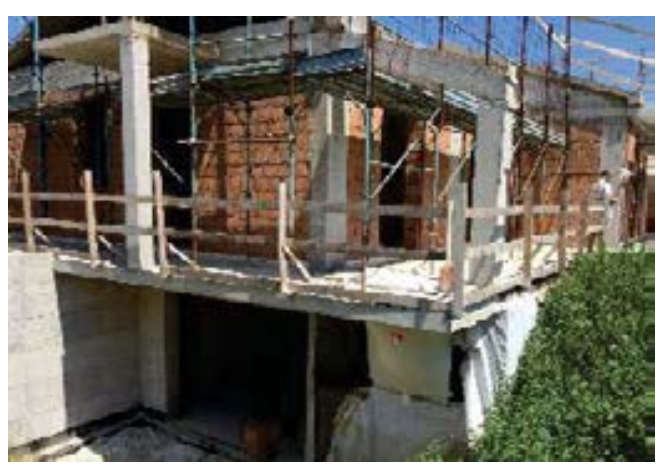

I1

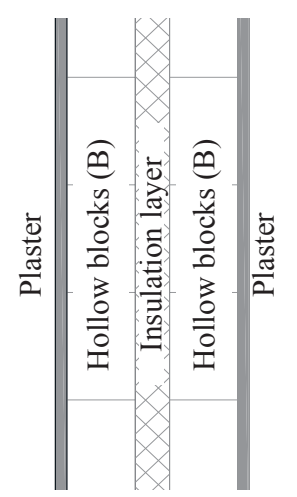

I2

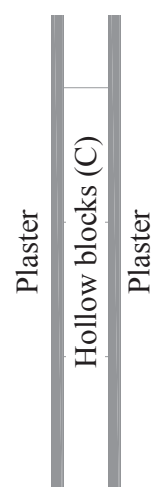

(b)

Figure 4: Real case study: a) building floor plans and picture during construction, b) infill masonry wall typologies.

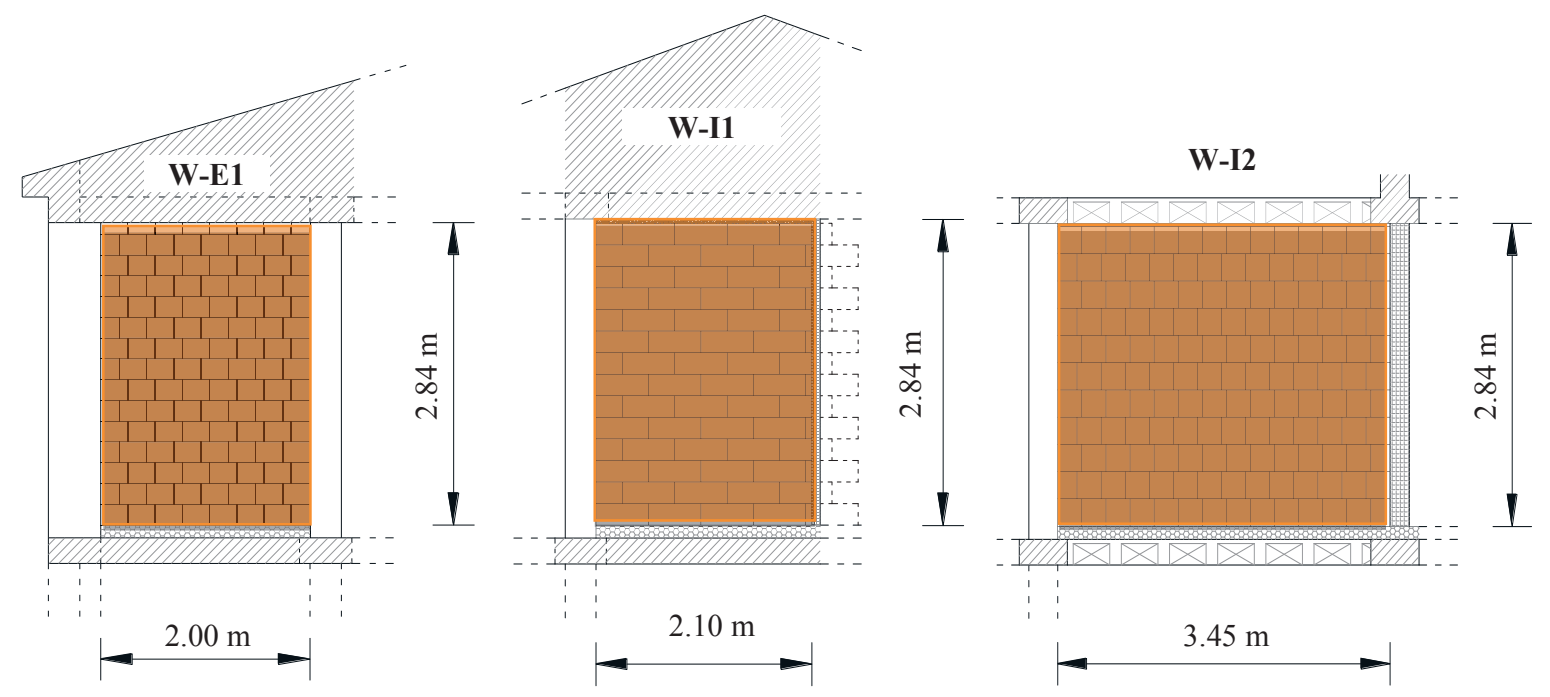

Figure 5: Geometry of tested infill masonry walls of the building. 


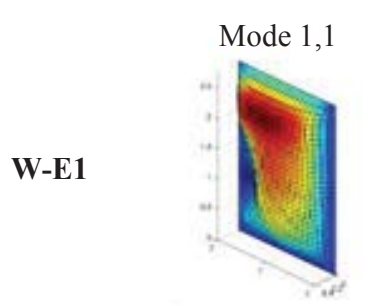

$64.73 \mathrm{~Hz}$

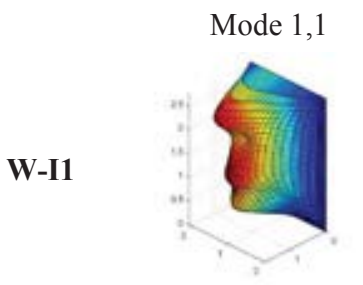

$41.81 \mathrm{~Hz}$

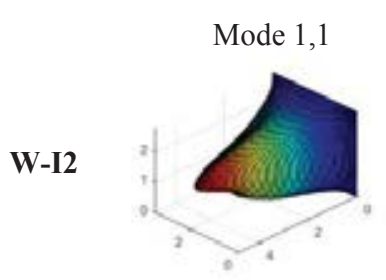

$22.10 \mathrm{~Hz}$

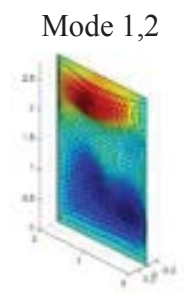

$88.93 \mathrm{~Hz}$

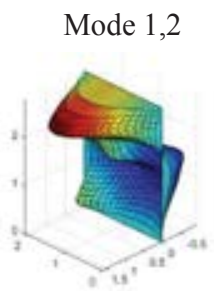

$72.09 \mathrm{~Hz}$

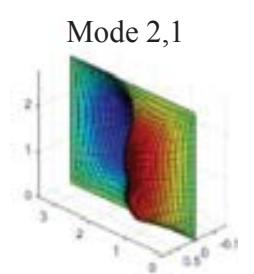

$40.28 \mathrm{~Hz}$

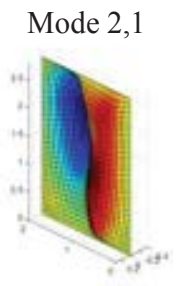

$161.74 \mathrm{~Hz}$

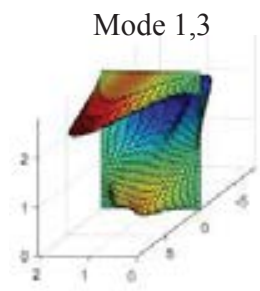

$122.53 \mathrm{~Hz}$

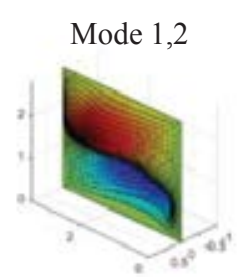

$49.88 \mathrm{~Hz}$

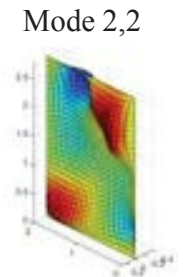

$201.52 \mathrm{~Hz}$

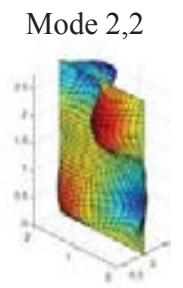

$151.56 \mathrm{~Hz}$

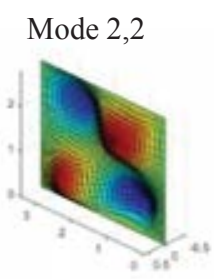

$64.57 \mathrm{~Hz}$

Figure 6: Experimental OOP modal parameters of tested infills.

The numerical investigation of infills is performed to estimate their elastic moduli. The f.e. model of the bare building is developed, modelling the r.c. frame with frame elements, while floors, slabs and retaining walls with shell elements. This model is preliminary calibrated based on experimental modal parameters of the whole building obtained from AVTs on the bare structure, with the aim to accurately predict the building dynamic behavior. Then, the investigated infills and the adjacent ones (to consider accurately the infill boundary conditions) are modelled with shell elements. Thus, three separated iterative procedures are performed, one for each investigated wall, and the elastic moduli are estimated once the convergence criteria (the same adopted before for the laboratory mock-up) are satisfied. In this case, four OOP modal parameters for each infill are considered in the iterative procedures to calculate the convergence criteria. Differently from the laboratory mock-up, the r.c. frame elements are modelled with beam elements, so the modelled infills have greater dimensions with respect to the real ones. Hence, the mass and elastic modulus of each infill is reduced, considering, for the sake of simplicity and with good approximation the mean percentage increment $\lambda$ of the infill dimensions of each panel. The estimated elastic moduli are $3000 \mathrm{MPa}$ for wall $\mathrm{W}-\mathrm{E} 1,2550 \mathrm{MPa}$ for $\mathrm{W}-\mathrm{I} 1$ and $3150 \mathrm{MPa}$ for wall W-I2. As before, to assess the reliability of these elastic moduli estimation, all infills are modelled within the global f.e. model of the building, considering their typology, openings and adopting the estimated elastic modulus for each infill typology. The numerical modal parameters of this infilled f.e. model are compared with the experimental ones obtained from AVTs measurements on the infilled structure, and the results are reported in Tab. 4. As can be noted, both frequencies and mode shapes are in very good agreement, proving the reliability of the proposed approach also when applied to real buildings. 
Table 4: Comparison between experimental and numerical modal parameters of the infilled building.

\begin{tabular}{cccc}
\hline Building & \multicolumn{2}{c}{ Frequency $[\mathrm{Hz}]$} & \multirow{2}{*}{ MAC } \\
mode & EXP & NUM & \\
\hline $1^{\text {st }}$ & 10.71 & 10.74 & 0.78 \\
$2^{\text {nd }}$ & 13.04 & 13.09 & 0.83 \\
$3^{\text {rd }}$ & 15.75 & 14.94 & 0.96 \\
\hline
\end{tabular}

\section{CONCLUSIONS}

A procedure to estimate the stiffness of infill masonry walls through a combined experimental and numerical procedure has been proposed in this paper. The procedure is firstly validated through investigations on a real-scale laboratory mock-up and then applied to a real infilled r.c. frame building. In both cases, the methodology reveals capable to furnish a reliable and realistic infill stiffness estimation, leading to obtain trustworthy f.e. models of the infilled structures. The proposed approach furnishes a practical and expeditious tool that can be suitably used to reduce uncertainties in the f.e. modelling of framed buildings when infills must be included. This should be fundamental when results of ambient vibration measurements need to be interpreted with refined f.e. models of structures or when results of structural health monitoring systems must be analyzed. The procedure has the great advantage of requiring fast and non-invasive dynamic tests on infills, thus it can be executed in new or in existing buildings.

\section{REFERENCES}

[1] L. Cavaleri, M. Fossetti, M. Papia, Infilled frames: developments in the evaluation of cyclic behavior under lateral loads. Structural Engineering and Mechanics, 21, 469-494, 2005 .

[2] D. Perrone, M. Leone, M. A. Aiello, Non-linear behaviour of masonry infilled rc frames: influence of masonry mechanical properties. Engineering Structures, 150, 875-891, 2017.

[3] G. Gabbianelli, D. Perrone, E. Brunesi, R. Monteiro, Seismic acceleration and displacement demand profiles of non-structural elements in hospital buildings. Buildings, 10(12), $1-19,2020$.

[4] J. Cheng, A. A. Koutras, P. B. Shing, Evaluation of collapse resistance of reinforced masonry wall systems by shake-table tests. Earthquake Engineering and Structural Dynamics, 50(2), 475-494, 2021.

[5] F. Gara, S. Carbonari, D. Roia, A. Balducci, L. Dezi, Seismic retrofit assessment of a school building through operational modal analysis and f.e. modelling. Journal of Structural Engineering, 147(1), article number 04020302, 2021.

[6] F. Gara, D. Arezzo, V. Nicoletti, S. Carbonari, Monitoring of the modal properties of a RC school building during the Central Italy seismic swarm. Journal of Structural Engineering (ASCE), DOI: 10.1061/(ASCE)ST.1943-541X.0003025, forthcoming.

[7] R. Astroza, H. Ebrahimian, J. P. Conte, J. I. Restrepo, T. C. Hutchinson, Influence of the construction process and nonstructural components on the modal properties of a fivestory building. Earthquake Engineering and Structural Dynamics, 45(7), 1063-1084, 2016. 
[8] K. Erazo, B. Moaveni, S. Nagarajaiah, Bayesian seismic strong-motion response and damage estimation with application to a full-scale seven story shear wall structure. Engineering Structures, 186, 146-160, 2019.

[9] M. Regni, D. Arezzo, S. Carbonari, F. Gara, D. Zonta, Effect of environmental conditions on the modal response of a 10-story reinforced concrete tower. Shock and Vibrations, ID 9476146, 2018.

[10] R. Vicente, H. Rodrigues, A. Arede, H. Varum, Simplified macro-model for infill masonry walls considering the out-of-plane behaviour. Earthquake Engineering and Structural Dynamics, 45(4), 507-524, 2016.

[11] F. Di Trapani, P. B. Shing, L. Cavaleri, Macroelement model for in-plane and out-ofplane responses of masonry infills in frame structures. Journal of Structural Engineering, 144(2), 1-13, 2018.

[12] A. B. Mehrabi, P. B. Shing, Finite element modelling of masonry-infilled RC frames, Journal of Structural Engineering, 123(5), 604-613, 1997.

[13] I. Koutromanos, A. Stavridis, P. B. Shing, K. Willam, Numerical modelling of masonryinfilled RC frames subjected to seismic loads. Composite Structures, 89(11-12), 10261037, 2011.

[14] G. Magenes, G. M. Calvi, In-plane seismic response of brick masonry walls. Earthquake Engineering and Structural Dynamics, 26(11), 1091-1112, 1997.

[15] J. Yacila, G. Camata, J. Salsavilca, N. Tarque, Pushover analysis of confined masonry walls using a 3-D macro-modelling approach. Engineering Structures, 201, article number 109731, 2019.

[16] A. Furtado, H. Rodrigues, A. Arede, H. Varum, Modal identification of infill masonry walls with different characteristics. Engineering Structures, 145, 118-134, 2017.

[17] A. De Angelis, M. R. Pecce, Out-of-plane structural identification of a masonry infill wall inside beam-column RC frame. Engineering Structures, 173, 546-558, 2018.

[18] V. Nicoletti, D. Arezzo, S. Carbonari, F. Gara, Expeditious methodology for the estimation of infill masonry wall stiffness through in-situ dynamic tests. Construction and Building Materials, 262, article number 120807, 2020.

[19] D. J. Ewins, Modal testing: theory, practice and application. John Wiley and Sons, 2009.

[20] EN1996-2. Eurocode 6: Design of masonry structures - Part 2: Design considerations, selection of materials and execution of masonry. European Community for Standardization, Brussels, 2006.

[21] A. K. Mitchell, C. R. Hazel, A simple frequency formula for clamped rectangular plates. Journal of Sound and Vibrations, 118(2), 271-281, 1986.

[22] R. J. Allemang, D. L. Brown, A correlation coefficient for modal vector analysis. $1^{\text {st }}$ Int. Modal Analysis Conference, Bethel, CT, USA, 1982. 